TECHNICAL TRANSACTIONS 11/2018

MECHANICS

DOI: $10.4467 / 2353737$ XCT.18.174.9430 SUBMISSION OF THE FINAL VERSION: 30/10/2018

\title{
Dominik Kwiatkowski
}

dkwiatkowski@pk.edu.pl

Institute of Applied Informatics, Faculty of Mechanical Engineering, Cracow University of Technology

\section{AIR CONSUMPTION SURVEY FOR PNEUMATIC CUSHION IN DIFFERENT} NOZZLE CONFIGURATIONS DURING MOVING LOADS

POMIAR ZUŻYCIA POWIETRZA DLA PODUSZKI PNEUMATYCZNEJ W RÓŻNYCH KONFIGURACJACH DYSZ PODCZAS PRZEMIESZCZANIA ŁADUNKU

\begin{abstract}
The subject of this paper concerns the search for structural solutions of pneumatic cushions $[1,2]$ in order to minimize the air consumption, operate at the lowest admissible pressure and compensate for the unevenness of the floor. The paper presents the solution with a multi-nozzle air outflow. This solution was obtained by a theoretical analysis, then a prototype of the device was made and laboratory tests were carried out.
\end{abstract}

Keywords: pneumatic cushions, air consumption, multi-nozzle air outflow

\section{Streszczenie}

Tematyka podjęta w referacie dotyczy poszukiwania rozwiązań konstrukcyjnych poduszek pneumatycznych $[1,2]$ w celu minimalizacji zużycia powietrza, pracy przy możliwie niskim ciśnieniu oraz uniezależnienia poduszki od wrażliwości na nierówności posadzki. W niniejszym artykule przedstawiono rozwiązanie z wielostrumieniowym wyplywem powietrza. Rozwiązanie to uzyskano w wyniku analizy teoretycznej, następnie wykonano prototyp urządzenia i przeprowadzono badania stanowiskowe.

Słowa kluczowe: poduszki pneumatyczne, zużycie powietrza, wielostrumieniowy wyplyw 


\section{Introduction}

In industrial companies lifting equipment, such as overhead cranes, winches, conveyors, is often used to transport heavy loads. It is usually characterized by large sizes, limited reach and high purchase costs. Today's industrial halls built with the use of modern technologies allow for obtaining horizontal and smooth work surfaces, including tilt $\alpha \leq 0.1$ o and a roughness of $\mathrm{Ra} \leq 12.5 \mu \mathrm{m}$.

This condition allows for applying transport systems with a pneumatic cushion. Pneumatic cushions are devices of small size, characterized by low height, which ranges from 30 to 40 . This simple design allows for sliding cushions under large loads and devices easily. In the laboratory of the Institute of Applied Informatics in the University of Technology, research is conducted on improving the parameters of pneumatic cushions through structural changes and the use of new control systems [2,3]. A research stand in the form of a transport platform (Fig. 1) allows for testing new solutions at different load values.

During operation, a pneumatic cushion creates a film of air which reduces friction with the ground. This film is produced by air that flows radially from the chambers in the lower part of the cushion. In the standard design of the air cushion [6], the air flows through one nozzle, placed in the central axis. Such a solution has some disadvantages, which include difficulties in achieving position stability and high sensitivity to surface irregularities. As part of this work, a solution consisting in increasing the number of outflow nozzles was proposed. Prototypes of a cushion with additional three and eight symmetrically placed nozzles were made. Then, a research was carried out on the impact of the number and deployment of nozzles on air demand through a pneumatic cushion depending on the load.

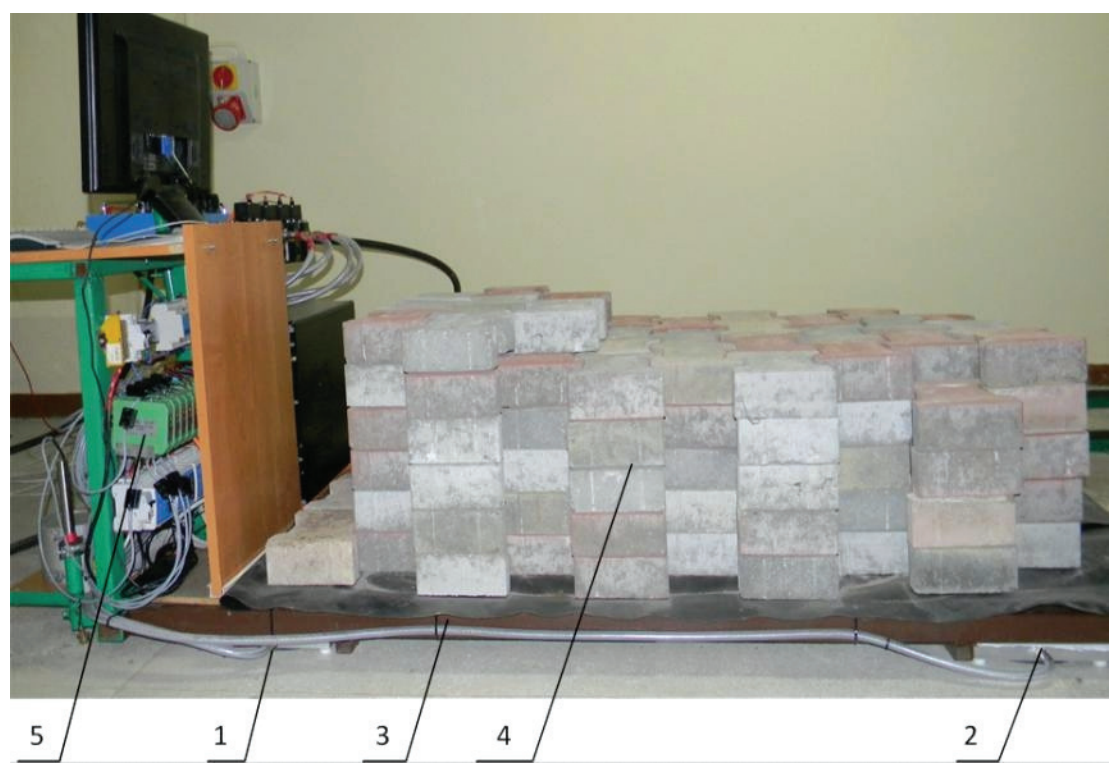

Fig. 1. Transport platform on pneumatic cushions, where: 1,2-pneumatic cushions, 3 - frame, 4 - load, 5 - measuring system 


\section{Mathematical model}

Before the start of the research, a mathematical model of a pneumatic cushion with one outlet nozzle, a model with four outlet nozzles and a model with nine nozzles were built. The models were used to determine the theoretical value of the required volume air flow at set values of other parameters such as pressure and temperature.

\subsection{Model of the pneumatic cushion with a single outlet}

The simplified cross section of the pneumatic cushion is shown in Figure 2.

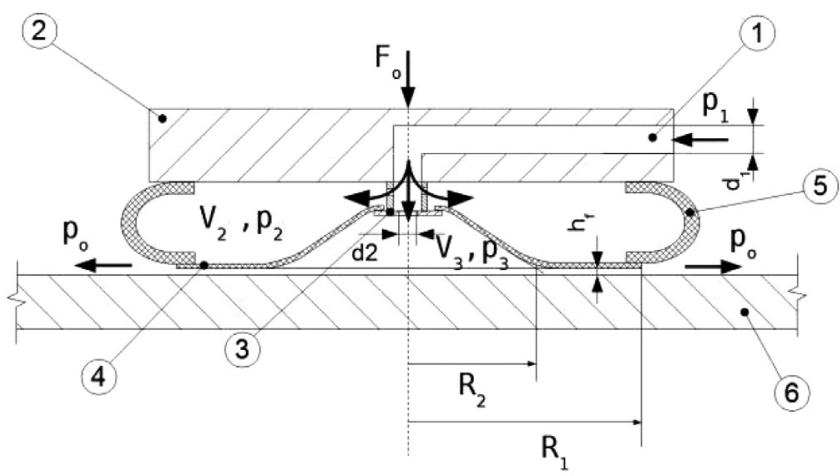

Fig. 2.View of the pneumatic cushion in cross section: 1 - supply collector, 2 - carrying plate, 3 - outlet nozzle, 4 - the bearing surface of the air chamber, 5 - the side surface of the air chamber,

$$
6 \text { - rigid surface }
$$

The mathematical model of the pneumatic cushion with one outlet nozzle included the following geometric parameters: $d_{1}$ - diameter of the supply collector, $p_{1}$ - inlet pressure, $d_{2}$ - diameter of the outlet nozzle, $F_{0}$ - force from the load, $p_{2}, p_{3}$ - pressure in the air chambers, $V_{2}, V_{3}$ - volume of the air chambers, $h_{f}$ - height of the air gap, $\mathrm{p}_{\mathrm{o}}-$ pressure ambient, $R_{1}, R_{2}-$ external and internal radius of the surface cooperating with the floor.

The calculation of the volume flow through the outlet nozzle was performed for the constant state, when the pressure in the side air chamber equalized $\left(p_{1}=p_{2}\right)$. With this assumption, the volumetric flow rate was calculated for the slit outlet nozzle $[4,6]$ :

where

$$
Q_{1}=\mu_{1} \cdot A_{1} \cdot v_{1}=\frac{\mu_{1} \cdot \pi \cdot d_{2}^{2}}{4} \cdot \sqrt{\frac{2}{\rho_{p}} \cdot\left(p_{1}-p_{3}\right)}
$$

$A_{1} \quad$ - cross-sectional area of the nozzle,

$v_{1} \quad$ - flow velocity,

$\mu_{1} \quad$ - discharge coefficient,

$d_{2}$ - diameter of the nozzle,

$p_{1}, p_{3}$ - pressure at the nozzle inlet and in the outlet chamber,

$\rho_{\mathrm{p}} \quad-$ air density. 
The flow of air $Q_{3}$ through the annular slit formed between the lower surface of the pneumatic cushion and the rigid surface was calculated by integrating the elementary flow $q_{r}$ through a segment of the ring-shaped surface of the thickness of dr within limits from $R_{2}$ to [5, 6]. After performing simple transformations, a formula was obtained describing the air flow rate at the pneumatic cushion outlet for a constant state:

where

$$
Q_{3}=\frac{\pi \cdot p_{3}}{6 \cdot \eta \cdot \ln \left(\frac{R_{1}}{R_{2}}\right)} \cdot h_{f}^{3}
$$

$h_{f} \quad-$ height of the air gap,

$p_{3}$ - pressure at the outlet chamber,

$\eta \quad-$ coefficient of dynamic,

$R_{1}, R_{2}$ - external and internal radius of the surface cooperating with the floor.

\subsection{Model of the pneumatic cushion with the quad outlets}

In this case, in the pneumatic cushion, apart from the main outlet nozzle to the lower chamber, three additional outlet nozzles were made, which were arranged on the lower surface of the cushion evenly at 120 degrees on the circle of radius $R_{d}=150 \mathrm{~mm}$. The mathematical model of a pneumatic cushion with four nozzles is defined according to the indications shown in Fig. 3. Assuming flow continuity in constant, volumetric flow rates at individual points of the pneumatic cushion can be noted using formulas (3)-(7). The flow rate through the supply channel nozzle can be noted in the following equation:

$$
Q_{1}=\mu_{1} \cdot A_{1} \cdot v_{1}=\mu_{1} \cdot \frac{\pi \cdot d_{1}^{2}}{4} \cdot \sqrt{\frac{2}{\rho_{0}} \cdot\left(p_{z a s}-p_{1}\right)}
$$

The flow through the nozzles according to the side and bottom chambers is expressed by the following equations:

$$
\begin{gathered}
Q_{2}=\mu_{2} \cdot A_{2} \cdot v_{2}=\mu_{2} \cdot \frac{\pi \cdot d_{2}^{2}}{4} \cdot \varphi \cdot \sqrt{v_{1}^{2}+\frac{2 \cdot \kappa}{\kappa-1} \cdot\left(\frac{p_{1}}{\rho_{1}}-\frac{p_{2}}{\rho_{2}}\right)} \\
Q_{3}=\mu_{3} \cdot A_{3} \cdot v_{3}=\mu_{3} \cdot \frac{\pi \cdot d_{3}^{2}}{4} \cdot \varphi \cdot \sqrt{v_{1}^{2}+\frac{2 \cdot \kappa}{\kappa-1} \cdot\left(\frac{p_{1}}{\rho_{1}}-\frac{p_{3}}{\rho_{3}}\right)}=Q_{5}
\end{gathered}
$$

The flow rate through each of the three nozzles placed in the lower part of the side chamber assuming uniformity of load and symmetry of the system:

$$
Q_{4}=\mu_{4} \cdot A_{4} \cdot v_{4}=\mu_{4} \cdot \frac{\pi \cdot d_{4}^{2}}{4} \cdot \sqrt{\frac{2}{\rho_{2}} \cdot\left(p_{2}-p_{3}\right)}
$$

The total flow of air through the gap between the pneumatic cushion and the ground: 


$$
Q_{6}=Q_{5}+3 \cdot Q_{4}=\frac{\pi \cdot p_{3}}{6 \cdot \eta \cdot \ln \left(R_{1} / R_{2}\right)} \cdot h_{f}^{3}
$$

where

$$
\begin{array}{ll}
A_{i}, v_{i} & - \text { area and flow velocity, } \\
\phi & \text { - velocity coefficient, } \\
\mu_{i} & \text { - discharge coefficient, } \\
d_{i} & \text { - diameter of the nozzle, } \\
p_{1}, p_{2}, p_{3} & \text { - pressure at the inlet, in the side chamber and in the bottom chamber, } \\
\rho_{i} & \text { - air density, } \\
\kappa & \text { - adiabatic coefficient. }
\end{array}
$$

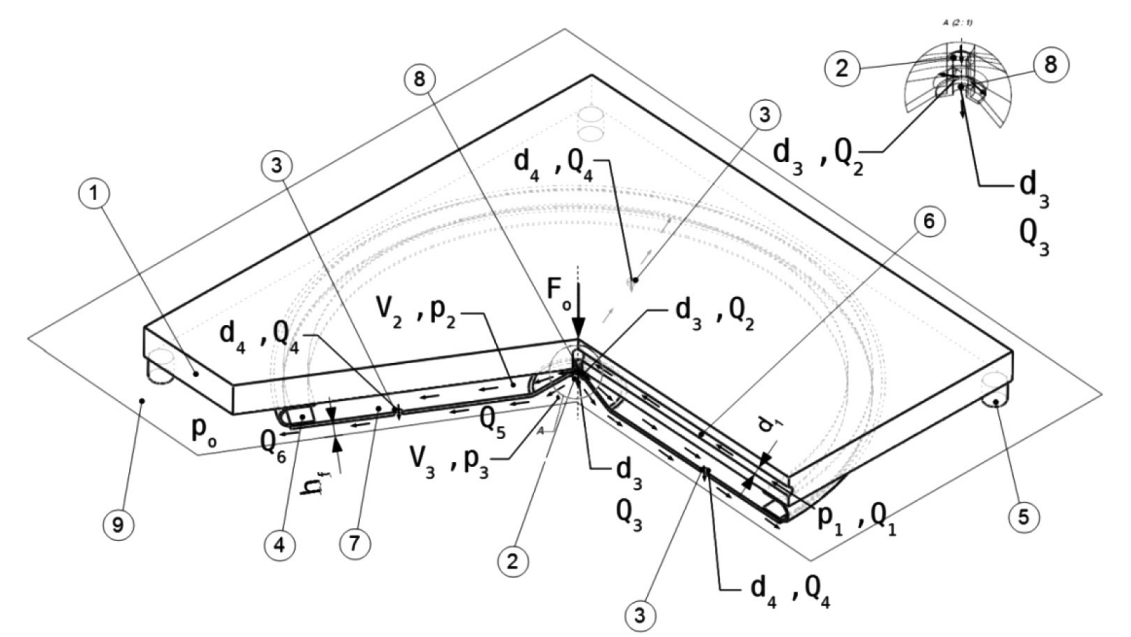

Fig. 3. A simplified model of the pneumatic cushion with the quad outlets: 1 - carrying plate,

2, 3 - nozzle, 4 - the side surface of the air chamber, 5 - support, 6 - supply collector, 7 - the bearing surface of the air chamber, 8 - mounting plate, 9 - rigid surface

\subsection{Model of the pneumatic cushion with nine outlet nozzles}

The model with nine nozzles was made analogously to the model with four nozzles, with eight nozzles evenly distributed on the circle every 45 degrees. The mathematical model of a pneumatic cushion with four nozzles is defined according to the indications shown in Fig. 4.

The flow rate in this case is described by equations (4)-(6), supplemented by the equation of the total air flow intensity, which in this case has the following form:

$$
Q_{6}=Q_{5}+8 \cdot Q_{4}=\frac{\pi \cdot p_{3}}{6 \cdot \eta \cdot \ln \left(\frac{R_{1}}{R_{2}}\right)} \cdot h_{f}^{3}
$$




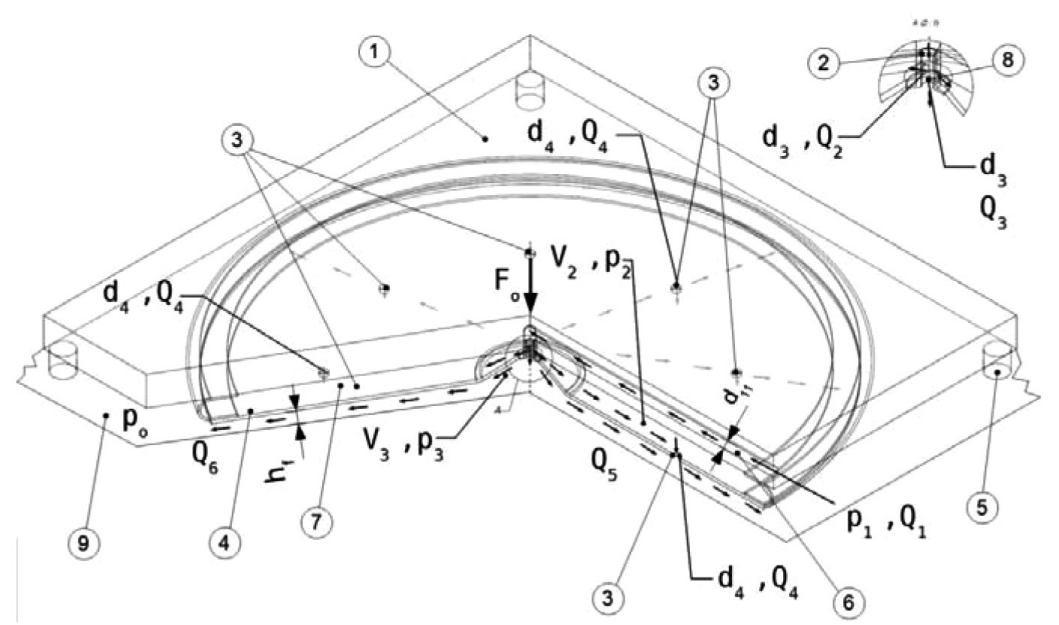

Fig. 4. A simplified model of the pneumatic cushion with nine outlet nozzles: 1 - carrying plate,

2, 3 - nozzle, 4 - the side surface of the air chamber, 5 - support, 6 - supply collector,

7 - the bearing surface of the air chamber, 8 - mounting plate, 9 - rigid surface

Theconstructedmathematicalmodelswereusedtodeterminethevolumevalueoftheflowrate as a function of supply pressure using the Maple [1] program.

\section{Experimental research}

In order to conduct experimental research, three prototypes of cushions with an external radius of $R_{1}=250 \mathrm{~mm}$ were built with one, four and nine outlet nozzles respectively. The appearance of the cushion with four nozzles is shown in Figure 5.

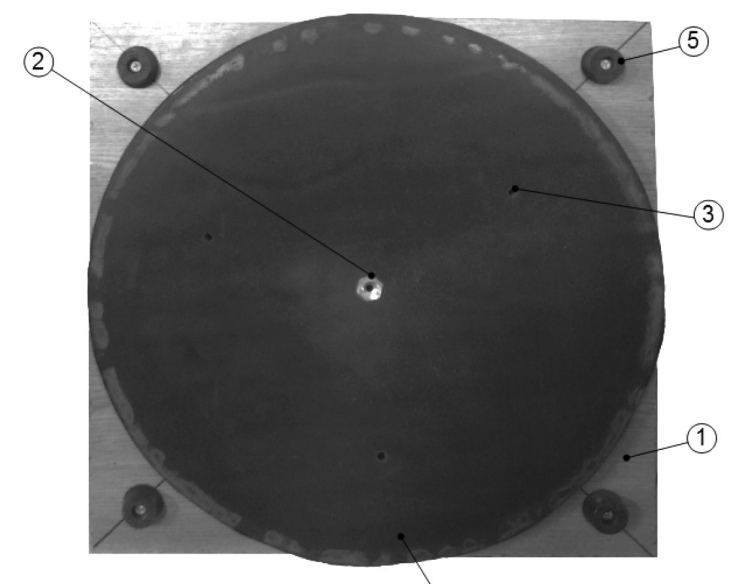

(4)

Fig. 5. The air cushion with the quad outlets: 1 - carrying plate, 2, 3 - outlet nozzle, 4 - the bearing surface of the air chamber, 5 - support 
The research plan included the determination of the volume flow rate for three pneumatic cushion prototypes made at different load and supply pressure values. The load was in each case carried out by means of a mass placed on the cushion: $m_{1}=202.5 \mathrm{~kg}, m_{2}=252.0 \mathrm{~kg}$, $m_{3}=324.0 \mathrm{~kg}$.

During the research, volumetric flow rates were determined depending on the supply pressure. Each graph contains the following curves: 1 - experimental testing at a standstill (without moving the system), 2 - experimental test during the movement of the pneumatic cushion, 3 - theoretical calculation at a standstill (without moving the system), 4 - theoretical calculation during the movement of the air cushion. Sample results of pneumatic cushion tests for the load of $m_{3}=324.0 \mathrm{~kg}$, are shown in Fig. 6-8.

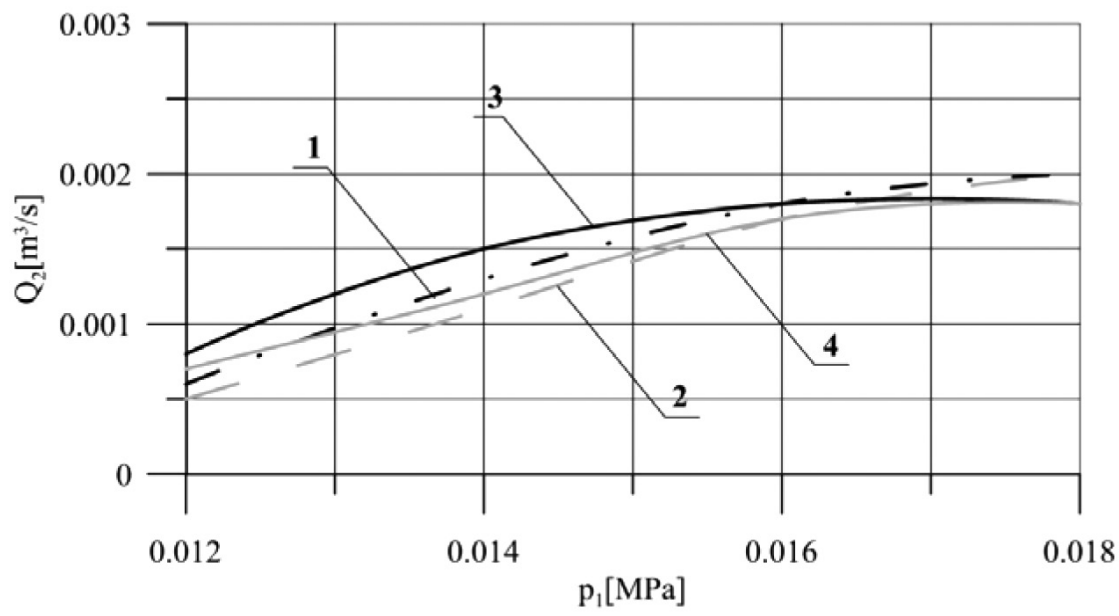

Fig. 6. The volumetric flow rate for the pneumatic cushion with a single outlet, loaded mass $m_{3}=324.0 \mathrm{~kg}$

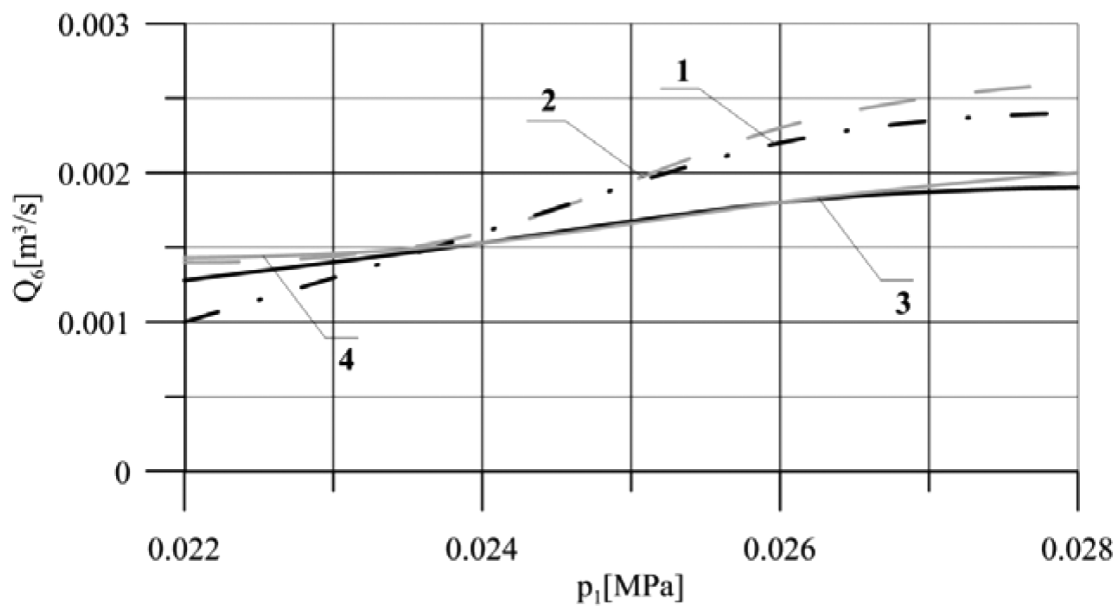

Fig. 7. The volumetric flow rate for the pneumatic cushion with quad outlets, loaded mass $m_{3}=324.0 \mathrm{~kg}$ 


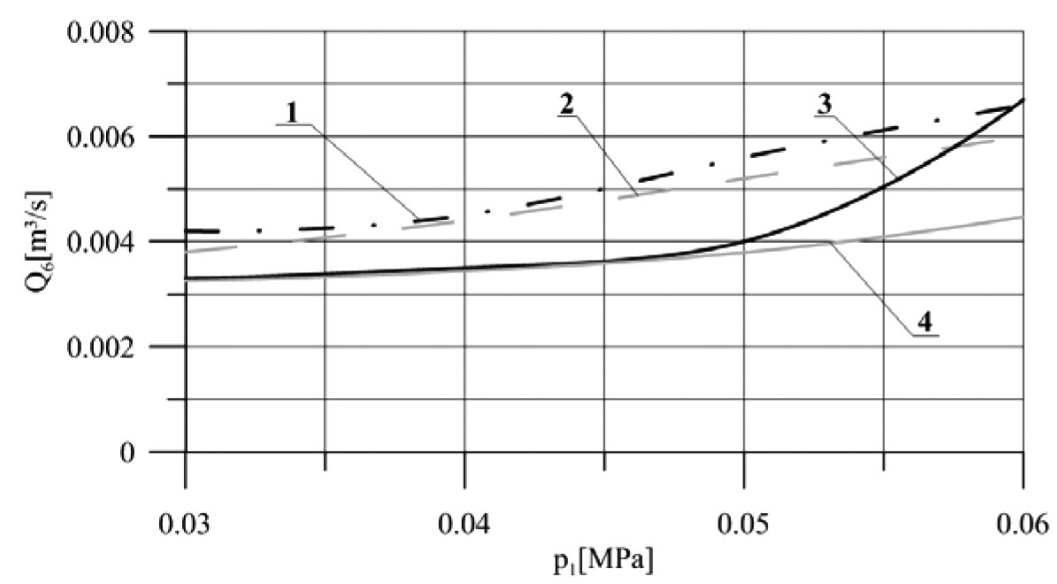

Fig. 8. The volumetric flow rate for the pneumatic cushion with nine outlet nozzles, loaded mass $m_{3}=324.0 \mathrm{~kg}$

The presented research results show a good correlation between theoretical calculationsand experimental tests. The maximum difference is up to $10 \%$ for the single-nozzle pneumatic cushion nd up to $20 \%$ for cushions with four and nine nozzles. Slightly larger differences can be observed during the movement of the cushions. This may be caused by surface irregularities which were not included in the mathematical model.

\section{Conclusions}

The paper studied air cushions with different numbers of nozzles. The dependence of the flow rate as a function of supply pressure for different loads was obtained. The comparison of test results showed that increasing the number of nozzles to four means about twice the increase in air flow required to create the air gap. In the case of a cushion with nine holes, this is an increase of about six fold. At the same time, increasing the number of nozzles leads to a significant improvement in the stabilization of the position of a pneumatic cushion. When lifting the load with the single-nozzle cushion, there was a visible waving effect. This effect was significantly reduced after using the cushion with four nozzles and practically disappeared after using the cushion with nine nozzles. Increasing the number of nozzles also led to a reduction in the force necessary to move the cushion with the load. The use of the cushion with four nozzles allowed for the reduction of force by about $20 \%$, while the cushion with nine nozzles enabledthe reduction of this force by about $50 \%$. 


\section{References}

[1] Krowiak A., Maple. Podręcznik, Helion, Gliwice 2012.

[2] Lisowski E., Filo G., Pressure control in air cushions of the mobile platform, Journal of KONES Powertrain and Transport, vol. 18 (2)/2011, 261-270.

[3] Lisowski E., Kwiatkowski D., Określenie podstawowych parametrów systemu pneumatycznego platformy transportowej na poduszkach pneumatycznych, Przegląd Mechaniczny, vol. 2 (12)/2012, 45-48.

[4] Messina A., Giannoccaro N., Gentile A., Experimenting and modeling the dynamics of pneumatic actuators controlled by the pulse width modulation (PWM) technique, Mechatronics, vol. 15 (7), 2005, 859-881.

[5] Moon J.-H., Lee B.-G., Modeling and sensitivity analysis of a pneumatic vibration isolation system with two air chambers, Mechanism and Machine Theory, vol. 45 (12)/2010, 1828-1850.

[6] Wołkow J., Dindorf R., Teoria i Obliczenia układów pneumatycznych, Wydawnictwo PK, Kraków 1995. 